\title{
Inhibitory Effect of Flavonoids on the Efflux of $N$-Acetyl 5-Aminosalicylic Acid Intracellularly Formed in Caco-2 Cells
}

\author{
Shin Yoshimura, Kentaro Kawano, Ryusuke Matsumura, Narumi Sugihara, and Koji Furuno
}

Faculty of Pharmacy and Pharmaceutical Sciences, Fukuyama University, Sanzou, Gakuen-cho, Fukuyama, Hiroshima 729-0292, Japan

Correspondence should be addressed to Koji Furuno, furuno@fupharm.fukuyama-u.ac.jp

Received 7 February 2009; Revised 13 May 2009; Accepted 1 June 2009

Recommended by Mostafa Z. Badr

$\mathrm{N}$-acetyl 5-aminosalicylic acid (5-AcASA) that was intracellularly formed from 5-aminosalicylic acid (5-ASA) at $200 \mu \mathrm{M}$ was discharged 5.3, 7.1, and 8.1-fold higher into the apical site than into the basolateral site during 1, 2, and 4-hour incubations, respectively, in Caco-2 cells grown in Transwells. The addition of flavonols $(100 \mu \mathrm{M})$ such as fisetin and quercetin with 5-ASA remarkably decreased the apically directed efflux of 5-AcASA. When 5-ASA $(200 \mu \mathrm{M})$ was added to Caco-2 cells grown in tissue culture dishes, the formation of 5-AcASA decreased, and, in addition, the formed 5-AcASA was found to be accumulated within the cells in the presence of such flavonols. Thus, the decrease in 5-AcASA efflux by such flavonols was attributed not only to the inhibition of $\mathrm{N}$-acetyl-conjugation of 5-ASA but to the predominant cellular accumulation of 5-AcASA. Various flavonoids also had both of the effects with potencies that depend on their specific structures. The essential structure of flavonoids was an absence of a hydroxyl substitution at the C5 position on the A-ring of flavone structure for the inhibitory effect on the $\mathrm{N}$-acetylconjugation of 5-ASA, and a presence of hydroxyl substitutions at the $\mathrm{C}^{\prime}$ or $\mathrm{C}^{\prime}$ ' position on the B-ring of flavone structure for the promoting effect on the cellular accumulation of 5-AcASA. Both the decrease in 5-AcASA apical efflux and the increase in 5-AcASA cellular accumulation were also caused by MK571 and indomethacin, inhibitors of MRPs, but not by quinidine, cyclosporin A, P-glycoprotein inhibitors, and mitoxantrone, a BCRP substrate. These results suggest that certain flavonoids suppress the apical efflux of 5-AcASA possibly by inhibiting MRPs pumps located on apical membranes in Caco-2 cells.

Copyright ( $\odot 2009$ Shin Yoshimura et al. This is an open access article distributed under the Creative Commons Attribution License, which permits unrestricted use, distribution, and reproduction in any medium, provided the original work is properly cited.

\section{Introduction}

Sulfasalazine used in the therapy of inflammatory bowel diseases, such as ulcerative colitis and Crohn's disease $[1,2]$. Ingested sulfasalazine passes to the colon without being absorbed in intestine and is split into 5-aminosalicylic acid (5-ASA) and sulfapyridine by colonic bacteria $[1,2]$. Most of 5-ASA is metabolized by $\mathrm{N}$-acetyl-conjugation in the form of $\mathrm{N}$-acetyl 5-aminosalicylic acid (5-AcASA) in the colonic epithelia, while sulfapyridine is quickly absorbed from the colon and metabolized in the liver [3-5]. It has been proposed that 5-ASA, the active moiety of sulfasalazine, exerts an antiinflammatory activity by inhibiting prostaglandin synthesis in colonic mucosa $[6,7]$. Some reports have shown that 5-AcASA has a potency as an inhibitor of prostaglandin synthesis comparable to that of 5-ASA [7], and therapeu- tically active when administered by enema to patients with ulcerative colitis [8]. However, 5-AcASA formed in colonic epithelia is immediately secreted into mucosal lumen and excreted in feces [9-11]. Thus, 5-AcASA is considered the portion that has already exerted therapeutical action within the bowel tissue [1-3, 9-11]. Zhou et al. reported that 5-AcASA was exclusively transported from the basolateral to the apical direction using human colon-derived Caco-2 cells [11]. However, the mechanism underlying the cellular transport of 5-AcASA has not extensively elucidated. It is well known that flavonoids (Figure 1), plant-derived compounds, alter the function of efflux transporters such as P-glycoprotein, that is, present in epithelium cells [12-14]. Recently, several researchers reported the inhibitory interaction of flavonoids with multidrug resistance-associated proteins (MRPs) that are responsible for active secretion of 

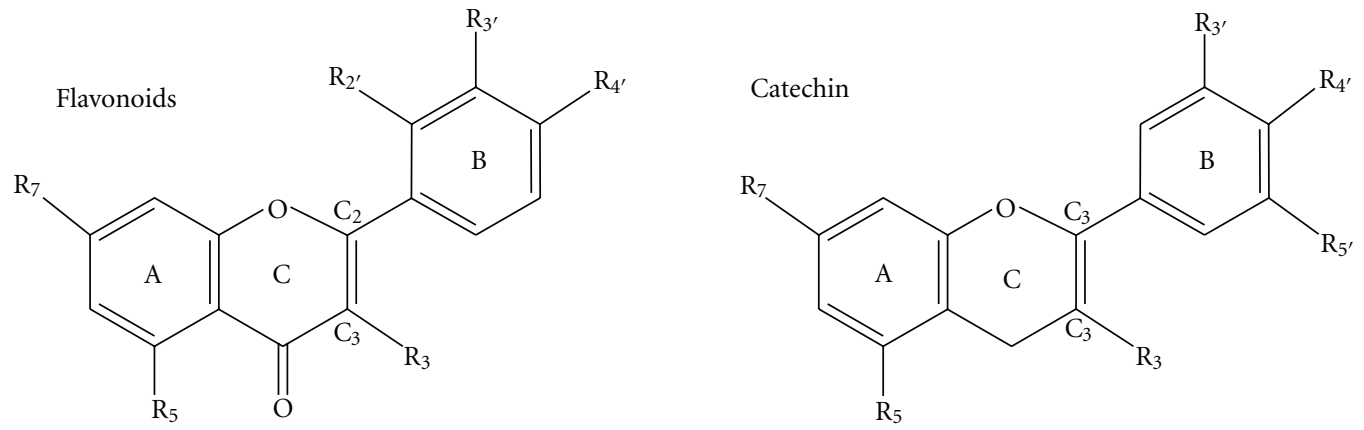

\begin{tabular}{lcccccccc}
\hline Flavonoids & $\mathrm{R}_{7}$ & $\mathrm{R}_{5}$ & $\mathrm{R}_{3}$ & $\mathrm{R}_{2^{\prime}}$ & $\mathrm{R}_{3^{\prime}}$ & $\mathrm{R}_{4^{\prime}}$ & $\mathrm{R}_{5^{\prime}}$ & $\mathrm{C}_{2}-\mathrm{C}_{3}$ \\
\hline Galangin (Gal) & $\mathrm{OH}$ & $\mathrm{OH}$ & $\mathrm{OH}$ & - & - & - & - & Double \\
Kaempferol (Kam) & $\mathrm{OH}$ & $\mathrm{OH}$ & $\mathrm{OH}$ & - & - & $\mathrm{OH}$ & - & Double \\
Quercetin (Que) & $\mathrm{OH}$ & $\mathrm{OH}$ & $\mathrm{OH}$ & - & $\mathrm{OH}$ & $\mathrm{OH}$ & - & Double \\
Taxifolin (Tax) & $\mathrm{OH}$ & $\mathrm{OH}$ & $\mathrm{OH}$ & - & $\mathrm{OH}$ & $\mathrm{OH}$ & - & Single \\
Fisetin (Fis) & $\mathrm{OH}$ & - & $\mathrm{OH}$ & - & $\mathrm{OH}$ & $\mathrm{OH}$ & - & Double \\
Morin (Mor) & $\mathrm{OH}$ & $\mathrm{OH}$ & $\mathrm{OH}$ & $\mathrm{OH}$ & - & $\mathrm{OH}$ & - & Double \\
Geraldol (Ger) & $\mathrm{OH}$ & - & $\mathrm{OH}$ & - & $\mathrm{OCH}_{3}$ & $\mathrm{OH}$ & - & Double \\
Isorhamnetin (Iso) & $\mathrm{OH}$ & $\mathrm{OH}$ & $\mathrm{OH}$ & - & $\mathrm{OCH}$ & $\mathrm{OH}$ & - & Double \\
Chrysin (Chr) & $\mathrm{OH}$ & $\mathrm{OH}$ & - & - & - & - & - & Double \\
Apigenin (Api) & $\mathrm{OH}$ & $\mathrm{OH}$ & - & - & - & $\mathrm{OH}$ & - & Double \\
Luteolin (Lut) & $\mathrm{OH}$ & $\mathrm{OH}$ & - & - & $\mathrm{OH}$ & $\mathrm{OH}$ & - & Double \\
Diosmetin (Dio) & $\mathrm{OH}$ & $\mathrm{OH}$ & - & - & $\mathrm{OH}$ & $\mathrm{OCH}$ & - & Double \\
3-Hydroxyflavone (3-OH) & - & - & $\mathrm{OH}$ & - & - & - & - & Double \\
5-Hydroxyflavone (5-OH) & - & $\mathrm{OH}$ & - & - & - & - & - & Double \\
7-Hydroxyflavone (7-OH) & $\mathrm{OH}$ & - & - & - & - & - & - & Double \\
7,4'-Dihydroxyflavone $\left(7,4^{\prime}-\mathrm{OH}\right)$ & $\mathrm{OH}$ & - & - & - & - & $\mathrm{OH}$ & - & Double \\
3' $^{\prime}, 4^{\prime}$-Dihydroxyflavone $\left(3^{\prime}, 4^{\prime}-\mathrm{OH}\right)$ & - & - & - & - & $\mathrm{OH}$ & $\mathrm{OH}$ & - & Double \\
7,3', 4 $^{\prime}$-Trihydroxyflavone $\left(7,3^{\prime}, 4^{\prime}-\mathrm{OH}\right)$ & $\mathrm{OH}$ & - & - & - & $\mathrm{OH}$ & $\mathrm{OH}$ & - & Double \\
Epicatechin (EC) & $\mathrm{OH}$ & $\mathrm{OH}$ & $\mathrm{OH}$ & - & $\mathrm{OH}$ & $\mathrm{OH}$ & - & Single \\
Epigallocatechin (EGC) & $\mathrm{OH}$ & $\mathrm{OH}$ & $\mathrm{OH}$ & - & $\mathrm{OH}$ & $\mathrm{OH}$ & $\mathrm{OH}$ & Single \\
\hline
\end{tabular}

FIGURE 1: Structure of flavonoids.

pharmacologically relevant drugs [15-20]. In this study, the effect of flavonoids and transporter inhibitors on the cellular efflux of 5-AcASA that was intracellularly formed from 5ASA was examined in Caco- 2 cells. Certain flavonoids and MRPs inhibitors displayed strong potency in decreasing the preferential apical efflux of 5-AcASA and in increasing the cellular accumulation of 5-AcASA in Caco-2 cells.

\section{Materials and Methods}

2.1. Materials. Materials and chemical reagents were purchased from the following companies: Transwells from Corning Costar (Cambridge, MA, USA); tissue culture dishes from Becton Dickinson Com. (Falcon; USA); flavonoids from Funakoshi Co. (Tokyo, Japan); 5-ASA and quinidine from Sigma-Aldrich Com. (Japan); MK571 from Alexis Biochemicals (Lausen, Switzerland); mitoxantrone from LKT Laboratories (MA, USA); indomethacin and other chemicals used from Wako Pure Chemical Co. (Osaka, Japan); and the Develosil RPAQUEOUS C-30-UG-3 column (4.6 I.D. $\times 150 \mathrm{~mm})$ from Nomura Chemical Co. (Aichi, Japan). Cyclosporin A was purchased from Sigma-Aldrich
Com. and Wako Pure Chemical Co. 5-AcASA was synthesized by the reaction of 5-ASA with acetic anhydride, as described by other researchers [21].

2.2. Efflux of 5-AcASA from Caco-2 Cells. Caco-2 cells were purchased from the Riken (no. RCB0988) and used as previously described [22]. The cell line was cultured in Dulbecco's modified Eagle's medium containing 12\% fetal calf serum and penicillin-streptomycin-amphotericin $\mathrm{B}$. The suspended cells were seeded on 6-well- polycarbonate Transwell inserts $\left(0.4 \mu \mathrm{m}\right.$ mean pore size, $4.7 \mathrm{~cm}^{2}$ growth area) at a density of $5 \times 10^{4}$ cells/dish, and then placed in an incubator in an atmosphere of 5\% $\mathrm{CO}_{2}-95 \%$ air at $37^{\circ} \mathrm{C}$. The Caco- 2 cells in the Transwell were grown for 3 weeks in Dulbecco's modified Eagle's medium containing fetal calf serum. The monolayers with transepithelial electric resistance of more than $250 \Omega \mathrm{cm}^{2}$ were used for transport studies. 5-ASA in a stock solution at $50 \mathrm{mM}$ was added to the apical chamber at a final concentration of $200 \mu \mathrm{M}$ after 10 minutes of the addition of flavonols. After incubation for 2 and 4 hours at $37^{\circ} \mathrm{C}, 50 \mu \mathrm{L}$ of the medium from both of the chambers was mixed with $50 \mu \mathrm{L}$ of $0.5 \mathrm{M}$ perchloric acid. 
TABLE 1: The effect of flavonols and transporter inhibitors on the apical and basolateral efflux of $N$-acetyl 5-aminosalicylic acid in Caco-2 cells. Caco-2 cells grown in Transwells were incubated with $200 \mu \mathrm{M}$ 5-ASA for 1, 2, and 4 hours in the presence of flavonols and transporter inhibitors at the concentration of $100 \mu \mathrm{M}$. Api: apical efflux of 5-AcASA, Baso: basolateral efflux of 5-AcASA. Each value represents the mean $\pm \mathrm{SD}$ of four to five experiments.

\begin{tabular}{|c|c|c|c|c|c|c|c|}
\hline & & Control & Fisetin & Quercetin & Morin & MK571 & Quinidine \\
\hline \multirow{3}{*}{$1 \mathrm{hr}$} & Api (nmol) & $1.01 \pm 0.14$ & $0.16 \pm 0.06^{* *}$ & $0.32 \pm 0.07^{* *}$ & $0.87 \pm 0.03$ & $0.47 \pm 0.13^{* *}$ & $0.91 \pm 0.16$ \\
\hline & Baso (nmol) & $0.19 \pm 0.02$ & $0.31 \pm 0.09^{* *}$ & $0.47 \pm 0.08^{* *}$ & $0.43 \pm 0.01^{* *}$ & $0.45 \pm 0.04^{* *}$ & $0.18 \pm 0.03$ \\
\hline & Api/Baso & $5.32 \pm 0.38$ & $0.52 \pm 0.11^{* *}$ & $0.68 \pm 0.06^{* *}$ & $2.02 \pm 0.04^{* *}$ & $1.04 \pm 0.19^{* *}$ & $5.06 \pm 0.21$ \\
\hline \multirow{3}{*}{$2 \mathrm{hr}$} & Api (nmol) & $2.05 \pm 0.28$ & $0.36 \pm 0.13^{* *}$ & $0.80 \pm 0.21^{* *}$ & $1.64 \pm 0.15$ & $1.05 \pm 0.05^{* *}$ & $1.96 \pm 0.59$ \\
\hline & Baso (nmol) & $0.29 \pm 0.04$ & $0.47 \pm 0.11^{* *}$ & $0.94 \pm 0.07^{* *}$ & $0.66 \pm 0.06^{* *}$ & $0.70 \pm 0.03^{* *}$ & $0.28 \pm 0.07$ \\
\hline & Api/Baso & $7.07 \pm 0.19$ & $0.77 \pm 0.16^{* *}$ & $0.85 \pm 0.16^{* *}$ & $2.48 \pm 0.04^{* *}$ & $1.50 \pm 0.11^{* *}$ & $7.00 \pm 0.18$ \\
\hline \multirow{3}{*}{$4 \mathrm{hr}$} & Api (nmol) & $5.04 \pm 0.61$ & $0.89 \pm 0.25^{* *}$ & $2.16 \pm 0.35^{* *}$ & $3.62 \pm 0.94$ & $2.30 \pm 0.22^{* *}$ & $4.61 \pm 0.72$ \\
\hline & Baso (nmol) & $0.62 \pm 0.08$ & $0.97 \pm 0.21^{* *}$ & $2.05 \pm 0.17^{* *}$ & $1.15 \pm 0.20^{*}$ & $1.14 \pm 0.09^{* *}$ & $0.59 \pm 0.10$ \\
\hline & Api/Baso & $8.13 \pm 0.27$ & $0.92 \pm 0.16^{* *}$ & $1.05 \pm 0.23^{* *}$ & $3.15 \pm 0.10^{* *}$ & $2.02 \pm 0.11^{* *}$ & $7.81 \pm 0.06$ \\
\hline
\end{tabular}

Significant difference from control $* P<.05, * * P<.01$.

2.3. Cellular Accumulation of 5-AcASA. Caco-2 cell line at passage of 40 was used for the experiments. The suspended cells in Dulbecco's modified Eagle's medium containing 12\% fetal calf serum and penicillin-streptomycin-amphotericin B were seeded on $35 \mathrm{~mm}$ plastic culture dishes at a density of $5 \times 10^{4}$ cells/dish. After seeding, the cells were cultured in a $37^{\circ} \mathrm{C}$ incubator under $5 \% \mathrm{CO}_{2}-95 \%$ air at $37^{\circ} \mathrm{C}$ for two weeks until the cells were fully differentiated into confluent enterocyte-like monolayers. Flavonoids, 5-ASA and other chemicals were dissolved in dimethyl sulfoxide and added to the medium at definite concentrations, with the final concentration of dimethyl sulfoxide about $1 \%$. After incubation for 2 hours, the cell monolayers were washed twice with Hanks balanced solution and harvested. The adequate volume of the medium and cell suspensions was treated with the same volume of $0.5 \mathrm{M}$ perchloric acid.

2.4. HPLC Analysis. Chromatographic separation and quantitative determination were carried out according to the HPLC analytical methods described previously [23]. A $0.1 \mathrm{~mL}$ aliquot of perchloric acid-treated sample was neutralized with $25 \mu \mathrm{L}$ of $1 \mathrm{M} \mathrm{NaOH}$ solution and $25 \mu \mathrm{L}$ of $0.5 \mathrm{M}$ Tris-HCl buffer ( $\mathrm{pH} 7.4$ ), and the total volume was adjusted to $0.5 \mathrm{~mL}$ with HPLC elution solvent. A $50 \mu \mathrm{L}$ aliquot of sample was injected onto a Develosil C-30-UG-3 (4.6 I.D. $\times 150 \mathrm{~mm}$ ) column adjusted to $40^{\circ} \mathrm{C}$, and 5-AcASA was separated by solution with a mixture of acetonitrile (4\%) and $20 \mathrm{mM}$ phosphate buffer ( $\mathrm{pH} 5.0$ solution) using a CCPD HPLC system equipped with an FS-8020 fluorescence detector (Tosoh Co., Japan). The flow rate of the mobile phase was $1.0 \mathrm{~mL} / \mathrm{min}$, and elution of 5-ASA and 5-AcASA was monitored at a fluorescence excitation wavelength of $310 \mathrm{~nm}$ and an emission wavelength of $480 \mathrm{~nm} .5$-ASA and 5-AcASA were eluted at 2.7 and 11.5 minutes, respectively. The quantitative determination of 5-AcASA was based upon the integration of fluorescence peak areas.

2.5. Statistical Analysis. The data in figures are given as the mean \pm S.D. of four to five experiments. Differences among the mean values were assessed by Dunnett's test using Stat100 (BIOSOFT, UK) or Student's $t$-test. A $P$ value of $<0.05$ was considered significant.

\section{Results}

The incubation of Caco-2 cells with 5-ASA formed only one peak of 5-ASA metabolite, which was identified as 5-AcASA by the same retention time as the synthesized standard in HPLC. The $\mathrm{N}$-acetyl-conjugative reaction of 5ASA in Caco-2 cells was saturated above $1 \mathrm{mM}$ of 5-ASA. The effect of flavonols and inhibitors of transporters on 5-AcASA efflux was examined using Caco-2 cell monolayers grown in Transwells which contained 1.5 and $2.6 \mathrm{~mL}$ Dulbecco's modified Eagle's medium in the apical and basolateral chambers, respectively. 5-ASA was loaded at $200 \mu \mathrm{M}$ in the apical chamber and 5-AcASA discharged from both of the apical and basolateral sites was measured. After 1, 2, and 4-hour incubation, amounts of 5-AcASA were 1.01, 2.05, and 5.04 nmoles in the apical chamber and 0.19, 0.29, and 0.62 nmoles in the basolateral chamber, respectively (Table 1). The apical efflux of 5-AcASA was 5.32, 7.07, and 8.13-fold higher than the basolateral efflux at 1,2, and 4hour incubation, respectively. When fisetin and quercetin $(100 \mu \mathrm{M})$ were added with 5-ASA to Caco-2 cells, the apical efflux of 5-AcASA decreased remarkably (Table 1). The basolateral efflux of 5-AcASA rather increased in the presence of such flavonols. The ratios for the apical to the basolateral efflux of 5-AcASA actually decreased to 0.52 and 0.68 at 1 hour, 0.77 and 0.85 at 2 hours, and 0.92 and 1.05 at 4 hour incubation, in the presence of fisetin and quercetin, respectively. Morin had a weaker effect than fisetin and quercetin. MK571, a MRPs inhibitor, showed a similar effect to quercetin; however, quinidine, a P-glycoprotein inhibitor, had no effects.

Figure 2 shows the time course of the amount of 5AcASA in the cells, medium, and their total (cells plus medium), and the percentage of cellular accumulation of 5-AcASA at 1,2, and 4-hour incubation in the presence of flavonols $(100 \mu \mathrm{M})$ with 5-ASA $(200 \mu \mathrm{M})$ in Caco-2 cells 


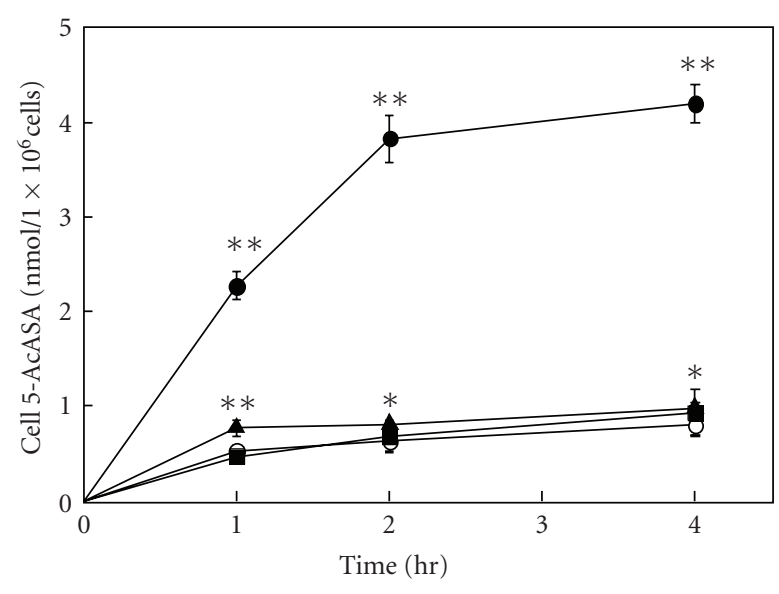

(a)

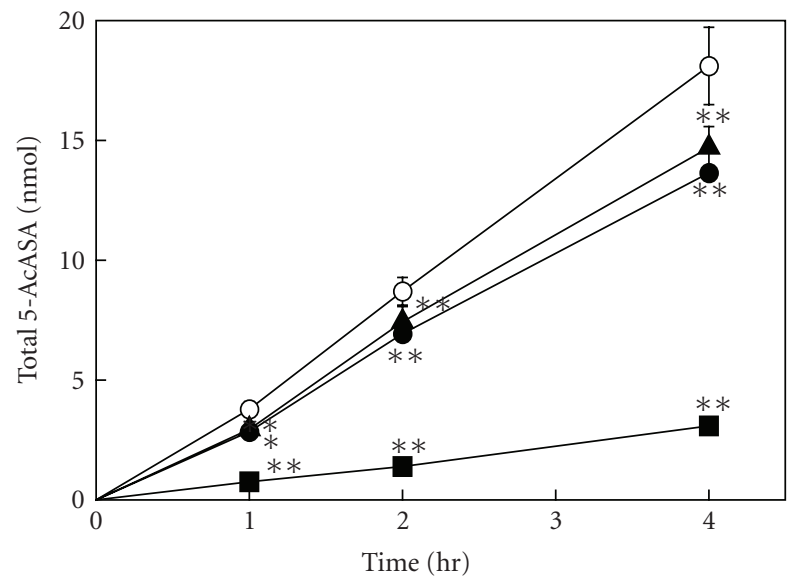

(c)

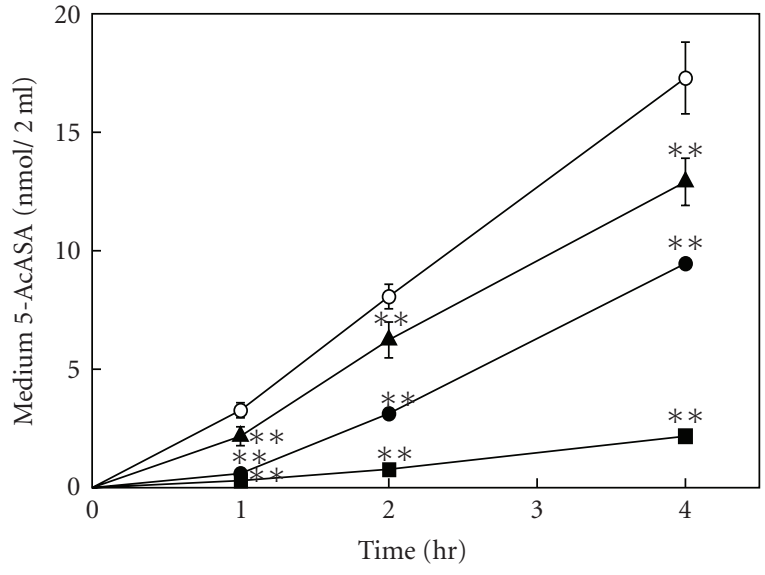

(b)

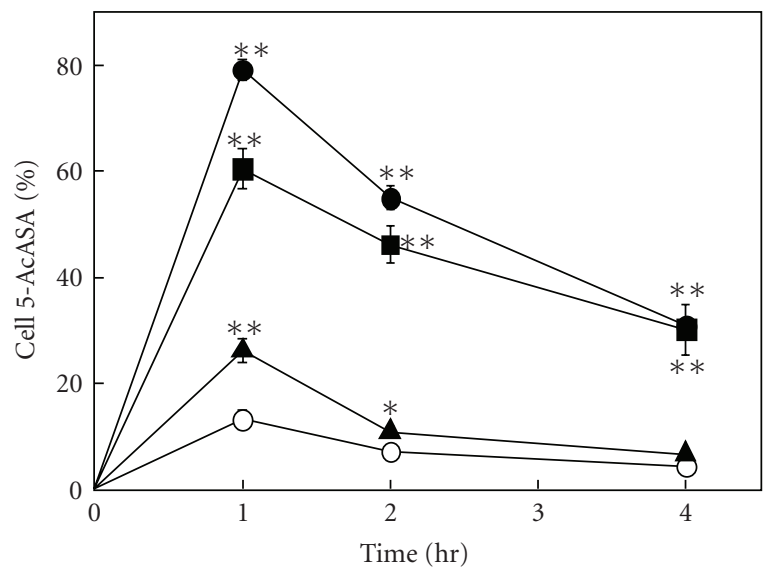

(d)

FIgure 2: (a) The time course curve of $\mathrm{N}$-acetyl 5-aminosalicylic acid in Caco-2 cells, (b) the medium and (c) the total, and (d) the cellular accumulation percent. Caco-2 cells grown in tissue culture dishes were incubated with $200 \mu \mathrm{M} 5$-ASA for 1, 2, and 4 hours in the absence (o) and the presence of quercetin $(\bullet)$, fisetin $(\boldsymbol{\bullet})$, and morin $(\boldsymbol{\Delta})$ at the concentration of $100 \mu \mathrm{M}$. Cell 5-AcASA (\%): (cells/cells plus medium) $\times$ 100. Each point represents the mean $\pm \mathrm{SD}$ of four to five experiments. Significant difference from control ${ }^{*} P<.05,{ }^{* *} P<.01$.

grown in tissue culture dishes. 5-AcASA was formed at the rate of $4 \mathrm{nmol} / \mathrm{h} / 1 \times 10^{6}$ cells during a 4 h-incubation period in the control cells. Flavonoids are potent inhibitors of $\mathrm{N}$-acetyltransferase [23]. Fisetin remarkably decreased the formation of 5-AcASA from 5-ASA in Caco-2 cells. Furthermore, a large amount of 5-AcASA was found in the cells treated by quercetin. The amount of 5-AcASA inside the control cells was 12 percent of the total 5AcASA at a 1 h-incubation and decreased to 6.3 and 3.2 percents at 2 and 4 -hour incubation, respectively. The cellular accumulation rate increased by several-fold than that of the control cells by quercetin and fisetin, and increased slightly by morin during a $4 \mathrm{~h}$-incubation period. Figure 3 shows the amount of 5-AcASA in the cells and medium in the presence of various flavonoids at a $2 \mathrm{~h}$ incubation. Flavonoids that lack a hydroxyl substitution at the C5 position on the A-ring had a strong inhibitory effect on the $\mathrm{N}$-acetyl-conjugation of 5-ASA. The total 5AcASA formed in the presence of fisetin, 7,3', $4^{\prime}$-OH flavone, $7,4^{\prime}-\mathrm{OH}$ flavone and geraldol decreased to $16.3,23.3,54.3$, and 68.3 percents of that of the control cells, respectively. Furthermore, most of flavonols and flavones caused an abundant cellular accumulation of 5-AcASA inside the cells. The cellular 5-AcASA accumulation was 52.7 percent of the total formed in the presence of quercetin, the most effective one among flavonoids tested (Table 2). Flavonoids that lack a C2-3 double bond or a carboxyl group at the C4 position on the C-ring, such as catechins and taxifolin, had no effects. The structural feature required for the potent effect on the cellular 5-AcASA accumulation was a presence of hydroxyl group on the B-ring of flavone structure. The effect of inhibitors or substrate of transporters on the cellular 5-AcASA accumulation was compared with flavonols at a 2 h-incubation with $200 \mu \mathrm{M}$ of 5-ASA in Caco-2 cells (Figure 4). MK-571 and indomethacin, MRPs inhibitors [24-26], increased in concentration-dependent manner the cellular 5-AcASA accumulation, while they did not affect the formation of 5-AcASA. MK-571 was more effective than indomethacin and showed equivalent efficacy to quercetin and fisetin. On the other hand, qunidine, a 


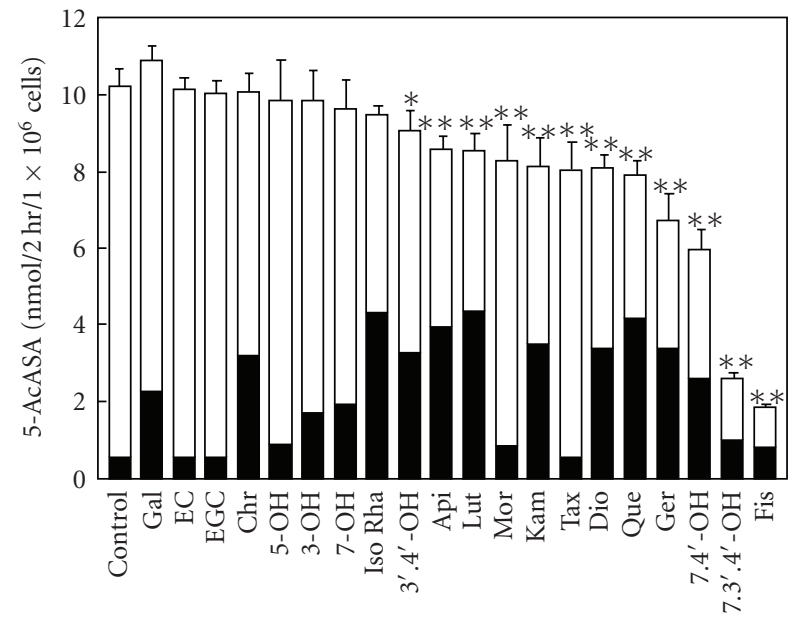

FIgUre 3: The amount of $N$-acetyl 5-aminosalicylic acid in Caco-2 cells and the medium. Caco- 2 cells grown in tissue culture dishes were incubated with $200 \mu \mathrm{M}$ 5-ASA for 2 hours in the presence of flavonoids at the concentration of $100 \mu \mathrm{M}$. 5-ASA in cells (Closed column), 5-ASA in medium (Open column). Each bar represents the mean $\pm \mathrm{SD}$ of four to five experiments. Significant difference from control ${ }^{*} P<.05,{ }^{* *} P<.01$.

P-glycoprotein inhibitor, and cyclosporine $\mathrm{A}$, an inhibitor of both P-glycoprotein and MRPs [27, 28], did not affect the cellular 5-AcASA accumulation. Mitoxantrone, a breast cancer resistance protein (BCRP) substrate [29], had no effects either at the concentration of $20 \mu \mathrm{M}$ (data not shown).

\section{Discussion}

5-AcASA that was formed from 5-ASA in the interior of cells was discharged preferentially to the apical direction compared to the basolateral direction in Caco- 2 cells grown in Transwells. Quercetin and fisetin remarkably decreased the apical efflux of 5-AcASA, while morin did with a less potency. The amount of 5-AcASA in Caco-2 cells and the medium was measured during a $4 \mathrm{~h}$-incubation with 5-ASA in the presence of such flavonols. Flavonoids are effective inhibitors of $\mathrm{N}$-acetyl-conjugation of 5-ASA in rat liver cytosol preparation [23]. Fisetin, in particular, exhibited strong inhibitory activity on 5-AcASA formation in Caco2 cells. Thus, the inhibition of 5-AcASA formation is likely to contribute largely to the decrease in the 5-AcASA efflux in the case of fisetin. However, quercetin showed a much weaker inhibitory effect on the 5-AcASA formation than fisetin. Surprisingly, the formed 5-AcASA was found to be accumulated inside the cells treated by flavonols. For quercetin, the cellular accumulation of 5-AcASA coincides with the decrease in 5-AcASA apical efflux. An increase in the basolateral efflux of 5-AcASA during an incubation of Transwells is probably due to the extensive cellular accumulation of 5-AcASA particularly in quercetin-treated cells.

A large group of flavonoids were examined for their inhibitory effects on the 5-AcASA formation as well as their promoting effects on the cellular 5-AcASA accumulation. A key chemical determinant necessary for exerting the strong inhibitory effect on the $\mathrm{N}$-acetyl-conjugation of 5-ASA was a lack of hydroxyl substitution at the $\mathrm{C} 5$ position on the A-ring of flavone structure such as fisetin and 7,3', $4^{\prime}-\mathrm{OH}$ favone. On the other hand, the structural requirement for the promoting effect on cellular 5-AcASA accumulation was a presence of hydroxyl substitution at the $\mathrm{C}^{\prime}$ or $\mathrm{C}^{\prime}$ position on the $\mathrm{B}$ ring of flavone structure. Therefore, the inhibition of 5AcASA formation and the promotion of cellular 5-AcASA accumulation by flavonoids seem to be caused by different mechanisms.

The results mentioned above suggest that 5-AcASA is pumped out by an active efflux transporter located on the apical membrane and certain flavonoids appear to play an important replacing role in the apical-directed transport of 5-AcASA in Caco-2 cells. Flavonoids are well-known modulators of the cellular transport of various substances mediated by P-glycoprotein which is localized on apical membranes in polarized cells [12-14]. Recently, several researchers reported the interaction of flavonoids with MRPs transporters. Walgren et al. reported that the efflux of quercetin $4^{\prime}$-betaglucoside across Caco- 2 cell monolayers was mediated by MRP2 [24]. Van Zanden et al. studied on the inhibitory effect of quercetin on MRPs pump-mediated efflux of calcein and vincristine, well-known MRPs substrates, in the MRP1 and MRP2 transfected MDCK cells [18-20]. They mentioned that MRP2 displayed higher selectivity for flavonoid-type inhibition than MRP1. Phase II metabolites of various drugs conjugated to glutathione, glucuronate, or sulfate are generally considered to be transported by MRPs-like transporters [30-32]. MRPs were characterized as the canalicular multispecific organic anion transporters that function in terminal secretion into bile canaliculus of endo- and xenobiotics such as acetaminophen metabolites, bilirubin glucuronides, 2,4dinitrophoenyl-S-glutathione, 17 $\beta$-glucuronosyl estradiol, and 4-methylumbelliferyl glucuronide that are conjugated in hepatocytes [33-35]. The transcellular transport of acetylconjugated 5-ASA from the basolateral site to the apical site in Caco-2 cell was first reported by Zhou et al. [11]. However, the transporter-mediated efflux of 5-AcASA has not been investigated thoroughly. To address the interest in involvement of transporters that are responsible for the 5-AcASA apical efflux in Caco-2 cells, several inhibitors of transporters were examined for their suppressing effect on the 5-AcASA apical efflux and promoting effect on the cellular 5-AcASA accumulation. MK571 and indomethacin, inhibitors of MRPs had similar effects to flavonoids. Quinidine, a P-glycoprotein inhibitor, and Cyclosporine $\mathrm{A}$, an inhibitor of P-glycoprotein and MRPs [27, 28], showed no effects. Absence of inhibitory activity of Cyclosporine A may be explained by substrate specificity of 5-AcASA for MRPs. Mitoxantrone, a substrate of BCRP [29], had no effects either. These results suggest that 5-AcASA is possibly pumped out by an MRPs-like transporter and certain flavonoids inhibit their efflux-pump activity in Caco2 cells.

Flavonoids are part of the human diet and possess many health benefits with low toxicity $[36,37]$. However, flavonoids are poorly absorbable compounds from the 
TABle 2: The cellular accumulation percent of in $\mathrm{N}$-acetyl 5-aminosalicylic acid Caco-2 cells. Caco-2 cells grown in tissue culture dishes were incubated with $200 \mu \mathrm{M} 5$-ASA for 2 hours in the presence of flavonoids at the concentration of $100 \mu \mathrm{M}$. Cellular accumulation percent: (cells/cells plus medium $) \times 100$. Each value represents the mean $\pm \mathrm{SD}$ of four to five experiments.

\begin{tabular}{lclc}
\hline Flavonoids & Cellular accumulation $(\%)$ & Flavonoids & Cellular accumulation (\%) \\
\hline Control & $5.5 \pm 0.8$ & $7,3^{\prime}, 4^{\prime}-$ OH flavone & $38.7 \pm 4.2^{* *}$ \\
Epicatechin & $5.7 \pm 0.3$ & Diosmetin & $41.8 \pm 2.4^{* *}$ \\
Epigallocatechin & $5.8 \pm 0.3$ & Fisetin & $42.7 \pm 1.2^{* *}$ \\
Taxifolin & $6.9 \pm 0.6$ & $7,4^{\prime}-$ OH lavone & $42.8 \pm 4.5^{* *}$ \\
5-OH flavone & $9.2 \pm 0.2^{* *}$ & Kaempferol & $43.1 \pm 0.7^{* *}$ \\
Morin & $9.9 \pm 0.3^{* *}$ & Isorhamnetin & $45.4 \pm 4.1^{* *}$ \\
3-OH flavone & $17.4 \pm 0.9^{* *}$ & Apigenin & $45.7 \pm 2.3^{* *}$ \\
7-OH flavone & $20.1 \pm 3.8^{* *}$ & Geraldol & $50.2 \pm 1.1^{* *}$ \\
Galangin & $21.3 \pm 3.1^{* *}$ & Luteolin & $50.7 \pm 3.2^{* *}$ \\
Chrysin & $31.7 \pm 3.5^{* *}$ & Quercetin & $52.7 \pm 2.5^{* *}$ \\
$3^{\prime}, 4^{\prime}-\mathrm{OH}$ flavones & $36.7 \pm 3.6^{* *}$ & & \\
\hline
\end{tabular}

Significant differences from control $* P<.05, * * P<.01$.
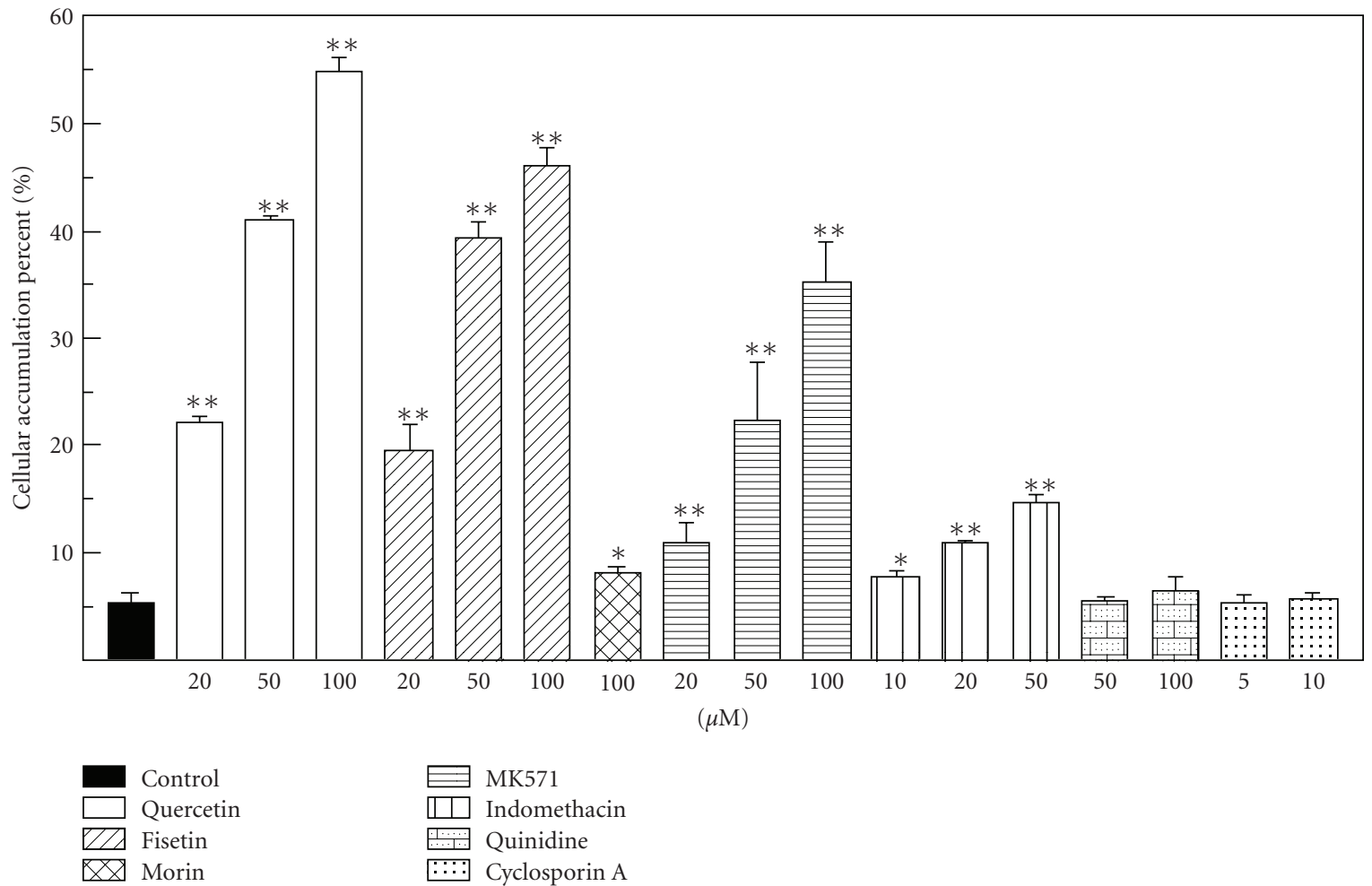

Figure 4: The effect of flavonols and transpoter inhibitors on the cellular accumulation of $N$-acetyl 5-aminosalicylic acid in Caco-2 cells. Caco-2 cells grown in tissue culture dishes were incubated with $200 \mu \mathrm{M}$ 5-ASA for 2 hours in the presence of flavonols and transporter inhibitors at the concentration of $100 \mu \mathrm{M}$. Cellular accumulation percent : (cells/cells plus medium) $\times 100$. Each bar represents the mean \pm $\mathrm{SD}$ of four to five experiments. Significant difference from control ${ }^{*} P<.05,{ }^{* *} P<.01$.

digestive tract in vertebrates $[38,39]$. When quercetin was given p.o. to the rats $(630 \mathrm{mg} / \mathrm{kg})$, approximately $20 \%$ of the total dose was absorbed from the digestive tract, more than $30 \%$ was decomposed in the intestinal microflora, and approximately $30 \%$ was excreted unchanged in the feces during 72 hours [38]. After a single oral dose of quercetin in humans $(4 \mathrm{~g})$, approximately $53 \%$ of the dose was recovered unchanged in the feces. Thus it was concluded that $1 \%$ of the original $4 \mathrm{~g}$ dose of quercetin was absorbed [39]. In this study, flavonoids were added at the concentration range from 20 to $100 \mu \mathrm{M}$ only into the apical compartment of Caco-2 cells in Transwells that faces to intestinal lumen in vivo. A high luminal level around $100 \mu \mathrm{M}$ of flavonoids is expected to be achieved with a single oral administration of a few hundred $\mathrm{mg}$ of flavonoids in humans. 
5-ASA, an active moiety of sulfasalazine, is immediately secreted into the luminal side from intestinal epithelia following extensive $\mathrm{N}$-acetyl-conjugation, and is finally excreted into feces [3-5]. Zhou et al. [11] reported that at luminal levels below $200 \mu \mathrm{g} / \mathrm{mL}$ (concentrations that are typically achieved by controlled release dosage forms), intestinal secretion of 5-AcASA accounts for more than $50 \%$ of the total 5-ASA elimination. Thus, 5-AcASA has been considered to be therapeutically nonactive portion [1-3, 9-11]. However, 5-AcASA has still antiinflammatory potential if the drug retains within the intestinal tissues [8]. The efficacy of 5-ASA therapy correlates with tissue delivery of 5-ASA, that is, determined by $\mathrm{N}$-acetylation and cellular discharge. The present study showed that certain flavonoids have the inhibitory effect on $\mathrm{N}$-acetyl-conjugation of 5-ASA and the suppressive effect on the 5-AcASA apical efflux in Caco-2 cells. Viewed in this light, both of these effects of flavonoids seem to be desirable in the treatment of inflammatory bowel diseases, since coadministration of flavonoids with 5-ASA is expected to increase the tissue levels of 5-ASA and 5-AcASA in intestine.

\section{References}

[1] K. M. Das, M. A. Eastwood, J. P. McManus, and W. Sircus, "Adverse reactions during salicylazosulfapyridine therapy and the relation with drug metabolism and acetylator phenotype," The New England Journal of Medicine, vol. 289, no. 10, pp. 491495, 1973.

[2] S. Ardizzone and G. B. Porro, "Comparative tolerability of therapies for ulcerative colitis," Drug Safety, vol. 25, no. 8, pp. 561-582, 2002.

[3] H. Allgayer, N. O. Ahnfelt, W. Kruis, et al., "Colonic Nacetylation of 5-aminosalicylic acid in inflammatory bowel disease," Gastroenterology, vol. 97, no. 1, pp. 38-41, 1989.

[4] E. Ricart, W. R. Taylor, E. V. Loftus, et al., "N-acetyltransferase 1 and 2 genotypes do not predict response or toxicity to treatment with mesalamine and sulfasalazine in patients with ulcerative colitis," American Journal of Gastroenterology, vol. 97, no. 7, pp. 1763-1768, 2002.

[5] B. Bat, J. Lodowska, A. Orchel, et al., "Evaluation of biotransformation of sulphasalazine in the colon epithelial Caco-2 cells," Acta Poloniae Pharmaceutica, vol. 61, pp. 8-10, 2004.

[6] P. Sharon, M. Ligumsky, D. Rachmilewitz, and U. Zor, "Role of prostaglandins in ulcerative colitis. Enhanced production during active disease and inhibition by sulfasalazine," Gastroenterology, vol. 75, no. 4, pp. 638-640, 1978.

[7] C. J. Hawkey and S. C. Truelove, "Inhibition of prostaglandin synthetase in human rectal mucosa," Gut, vol. 24, no. 3, pp. 213-217, 1983.

[8] C. P. Willoughby, J. Piris, and S. C. Truelove, "The effect of topical $\mathrm{N}$-acetyl-5-aminosalicylic acid in ulcerative colitis," Scandinavian Journal of Gastroenterology, vol. 15, no. 6, pp. 715-719, 1980.

[9] P. H. Layer, H. Goebell, J. Keller, A. Dignass, and U. Klotz, "Delivery and fate of oral mesalamine microgranules within the human small intestine," Gastroenterology, vol. 108, no. 5, pp. 1427-1433, 1995.

[10] S. Bondesen, "Intestinal fate of 5-aminosalicylic acid: regional and systemic kinetic studies in relation to inflammatory bowel disease," Pharmacology and Toxicology, vol. 81, supplement 2, pp. 1-28, 1997.

[11] S. Y. Zhou, D. Fleisher, L. H. Pao, C. Li, B. Winward, and E. M. Zimmermann, "Intestinal metabolism and transport of 5aminosalicylate," Drug Metabolism and Disposition, vol. 27, no. 4, pp. 479-485, 1999.

[12] A. Di Pietro, G. Conseil, J. M. Pérez-Victoria, et al., "Modulation by flavonoids of cell multidrug resistance mediated by P-glycoprotein and related ABC transporters," Cellular and Molecular Life Sciences, vol. 59, no. 2, pp. 307-322, 2002.

[13] S. Zhang and M. E. Morris, "Effects of the flavonoids biochanin A, morin, phloretin, and silymarin on Pglycoprotein-mediated transport," Journal of Pharmacology and Experimental Therapeutics, vol. 304, no. 3, pp. 1258-1267, 2003.

[14] M. Takano, R. Yumoto, and T. Murakami, "Expression and function of efflux drug transporters in the intestine," Pharmacology and Therapeutics, vol. 109, no. 1-2, pp. 137-161, 2006.

[15] E. M. Leslie, Q. Mao, C. J. Oleschuk, R. G. Deeley, and S. P. C. Cole, "Modulation of multidrug resistance protein 1 (MRP1/ABCC1) transport and ATpase activities by interaction with dietary flavonoids," Molecular Pharmacology, vol. 59, no. 5, pp. 1171-1180, 2001.

[16] M. Bobrowska-Hägerstrand, A. Wróbel, L. Mrówczyńska, et al., "Flavonoids as inhibitors of MRP1-like efflux activity in human erythrocytes. A structure-activity relationship study," Oncology Research, vol. 13, no. 11, pp. 463-469, 2003.

[17] B. Łania-Pietrzak, A. B. Hendrich, J. Zugaj, and K. Michalak, "Metabolic O-demethylation does not alter the influence of isoflavones on the biophysical properties of membranes and MRP1-like protein transport activity," Archives of Biochemistry and Biophysics, vol. 433, no. 2, pp. 428-434, 2005.

[18] J. J. Van Zanden, H. M. Wortelboer, S. Bijlsma, et al., "Quantitative structure activity relationship studies on the flavonoid mediated inhibition of multidrug resistance proteins 1 and 2," Biochemical Pharmacology, vol. 69, no. 4, pp. 699$708,2005$.

[19] J. J. Van Zanden, A. De Mul, H. M. Wortelboer, et al., "Reversal of in vitro cellular MRP1 and MRP2 mediated vincristine resistance by the flavonoid myricetin," Biochemical Pharmacology, vol. 69, no. 11, pp. 1657-1665, 2005.

[20] J. J. Van Zanden, H. van der Woude, J. Vaessen, et al., “The effect of quercetin phase II metabolism on its MRP1 and MRP2 inhibiting potential," Biochemical Pharmacology, vol. 74, no. 2, pp. 345-351, 2007.

[21] E. Brendel, I. Meineke, D. Witsch, and M. Zschunke, "Simultaneous determination of 5-aminosalicylic acid and 5acetylaminosalicylic acid by high-performance liquid chromatography," Journal of Chromatography, vol. 385, pp. 299304, 1987.

[22] N. Sugihara, K. Toyama, A. Michihara, K. Akasaki, H. Tsuji, and K. Furuno, "Effect of benzo[a]pyrene on P-glycoproteinmediated transport in Caco-2 cell monolayer," Toxicology, vol. 223, no. 1-2, pp. 156-165, 2006.

[23] Y. Mizoyama, H. Takaki, N. Sugihara, and K. Furuno, "Inhibitory effect of flavonoids on $\mathrm{N}$-acetylation of 5aminosalicylic acid in cultured rat hepatocytes," Biological and Pharmaceutical Bulletin, vol. 27, no. 9, pp. 1455-1458, 2004.

[24] R. A. Walgren, K. J. Karnaky Jr., G. E. Lindenmayer, and T. Walle, "Efflux of dietary flavonoid quercetin 4 '- $\beta$-glucoside across human intestinal Caco-2 cell monolayers by apical 
multidrug resistance-associated protein-21," Journal of Pharmacology and Experimental Therapeutics, vol. 294, no. 3, pp. 830-836, 2000.

[25] J. Hong, J. D. Lambert, S.-H. Lee, P. J. Sinko, and C. S. Yang, "Involvement of multidrug resistance-associated proteins in regulating cellular levels of (-)-epigallocatechin-3-gallate and its methyl metabolites," Biochemical and Biophysical Research Communications, vol. 310, no. 1, pp. 222-227, 2003.

[26] J. Schrickx, Y. Lektarau, and J. Fink-Gremmels, "Ochratoxin A secretion by ATP-dependent membrane transporters in Caco2 cells," Archives of Toxicology, vol. 80, no. 5, pp. 243-249, 2006.

[27] Y. Honda, F. Ushigome, N. Koyabu, et al., "Effects of grapefruit juice and orange juice components on P-glycoprotein- and MRP2-mediated drug efflux," British Journal of Pharmacology, vol. 143, no. 7, pp. 856-864, 2004.

[28] K. Takasuna, T. Hagiwara, K. Watanabe, et al., "Optimal antidiarrhea treatment for antitumor agent irinotecan hydrochloride (CPT-11)-induced delayed diarrhea," Cancer Chemotherapy and Pharmacology, vol. 58, no. 4, pp. 494-503, 2006.

[29] K. Yanase, S. Tsukahara, J. Mitsuhashi, and Y. Sugimoto, "Functional SNPs of the breast cancer resistance proteintherapeutic effects and inhibitor development," Cancer Letters, vol. 234, no. 1, pp. 73-80, 2006.

[30] G. Jedlitschky, I. Leier, U. Buchholz, K. Barnouin, G. Kurz, and D. Keppler, "Transport of glutathione, glucuronate, and sulfate conjugates by the MRP gene-encoded conjugate export pump," Cancer Research, vol. 56, no. 5, pp. 988-994, 1996.

[31] J. Konig, A. T. Nies, Y. Cui, I. Leier, and D. Keppler, "Conjugate export pumps of the multidrug resistance protein (MRP) family: localization, substrate specificity, and MRP2-mediated drug resistance," Biochimica et Biophysica Acta, vol. 1461, no. 2, pp. 377-394, 1999.

[32] H. Suzuki and Y. Sugiyama, "Single nucleotide polymorphisms in multidrug resistance associated protein 2 (MRP2/ABCC2): its impact on drug disposition," Advanced Drug Delivery Reviews, vol. 54, pp. 1319-1331, 2002.

[33] Y. Gotoh, H. Suzuki, S. Kinoshita, T. Hirohashi, Y. Kato, and Y. Sugiyama, "Involvement of an organic anion transporter (canalicular multispecific organic anion transporter/multidrug resistance-associated protein 2) in gastrointestinal secretion of glutathione conjugates in rats," Journal of Pharmacology and Experimental Therapeutics, vol. 292, no. 1, pp. 433-439, 2000.

[34] A. L. Slitt, N. J. Cherrington, J. M. Maher, and C. D. Klaassen, "Induction of multidrug resistance protein 3 in rat liver is associated with altered vectorial excretion of acetaminophen metabolites," Drug Metabolism and Disposition, vol. 31, no. 9, pp. 1176-1186, 2003.

[35] M. J. Zamek-Gliszczynski, K. A. Hoffmaster, J. E. Humphreys, X. Tian, K.-I. Nezasa, and K. L. R. Brouwer, "Differential involvement of Mrp2 (Abcc2) and Bcrp (Abcg2) in biliary excretion of 4-methylumbelliferyl glucuronide and sulfate in the rat," Journal of Pharmacology and Experimental Therapeutics, vol. 319, no. 1, pp. 459-467, 2006.

[36] B. Havsteen, "Flavonoids, a class of natural products of high pharmacological potency," Biochemical Pharmacology, vol. 32, no. 7, pp. 1141-1148, 1983.

[37] N. C. Cook and S. Samman, "Flavonoids-chemistry, metabolism, cardioprotective effects, and dietary sources," Journal of Nutritional Biochemistry, vol. 7, no. 2, pp. 66-76, 1996.
[38] I. Ueno, N. Nakano, and I. Hirono, "Metabolic fate of $\left[{ }^{14} \mathrm{C}\right]$ quercetin in the ACl rat," Japanese Journal of Experimental Medicine, vol. 53, no. 1, pp. 41-50, 1983.

[39] R. Gugler, M. Leschik, and H. J. Dengler, "Disposition of quercetin in man after single oral and intraveneous doses," European Journal of Clinical Pharmacology, vol. 9, pp. 229-234, 1975. 

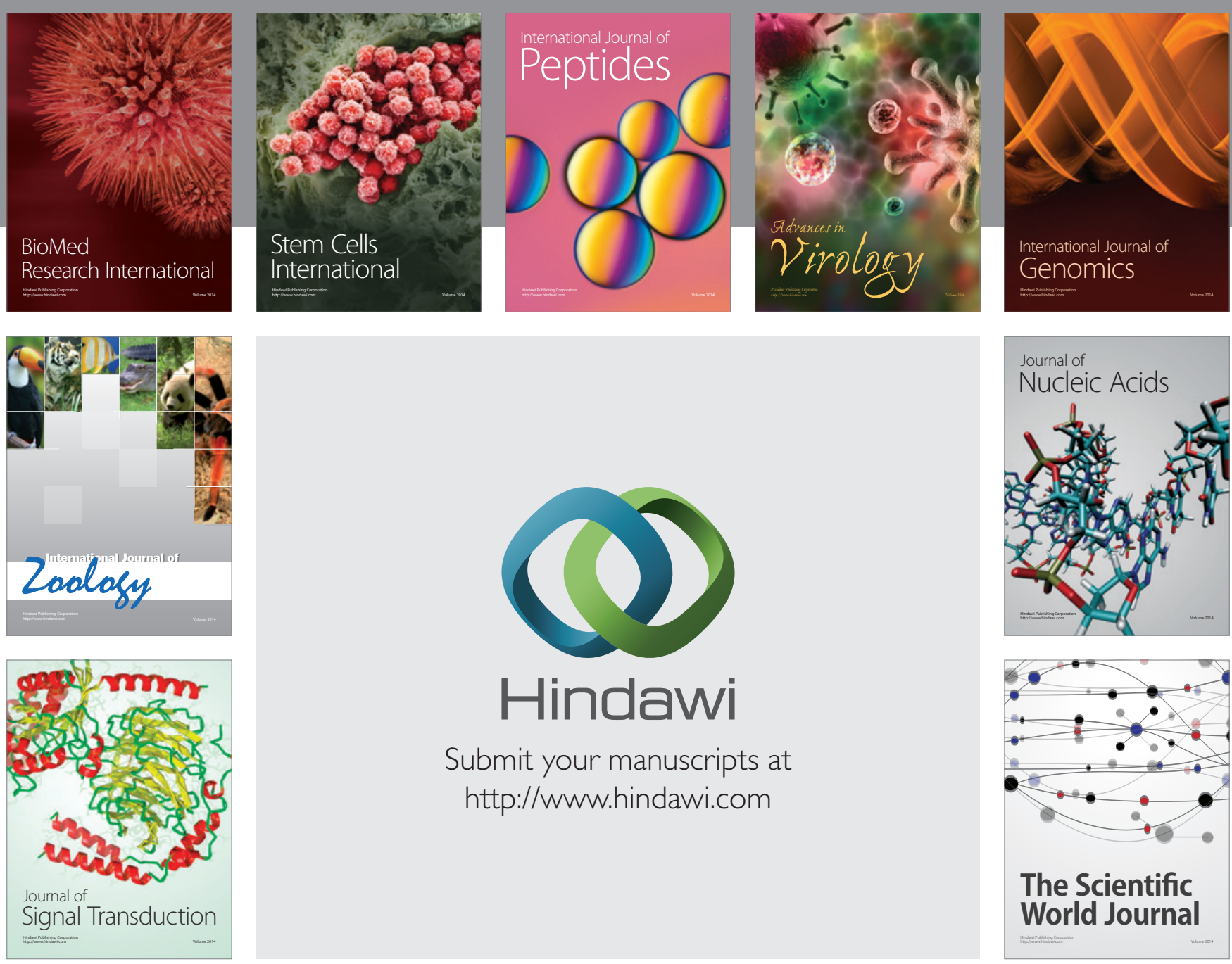

Submit your manuscripts at

http://www.hindawi.com
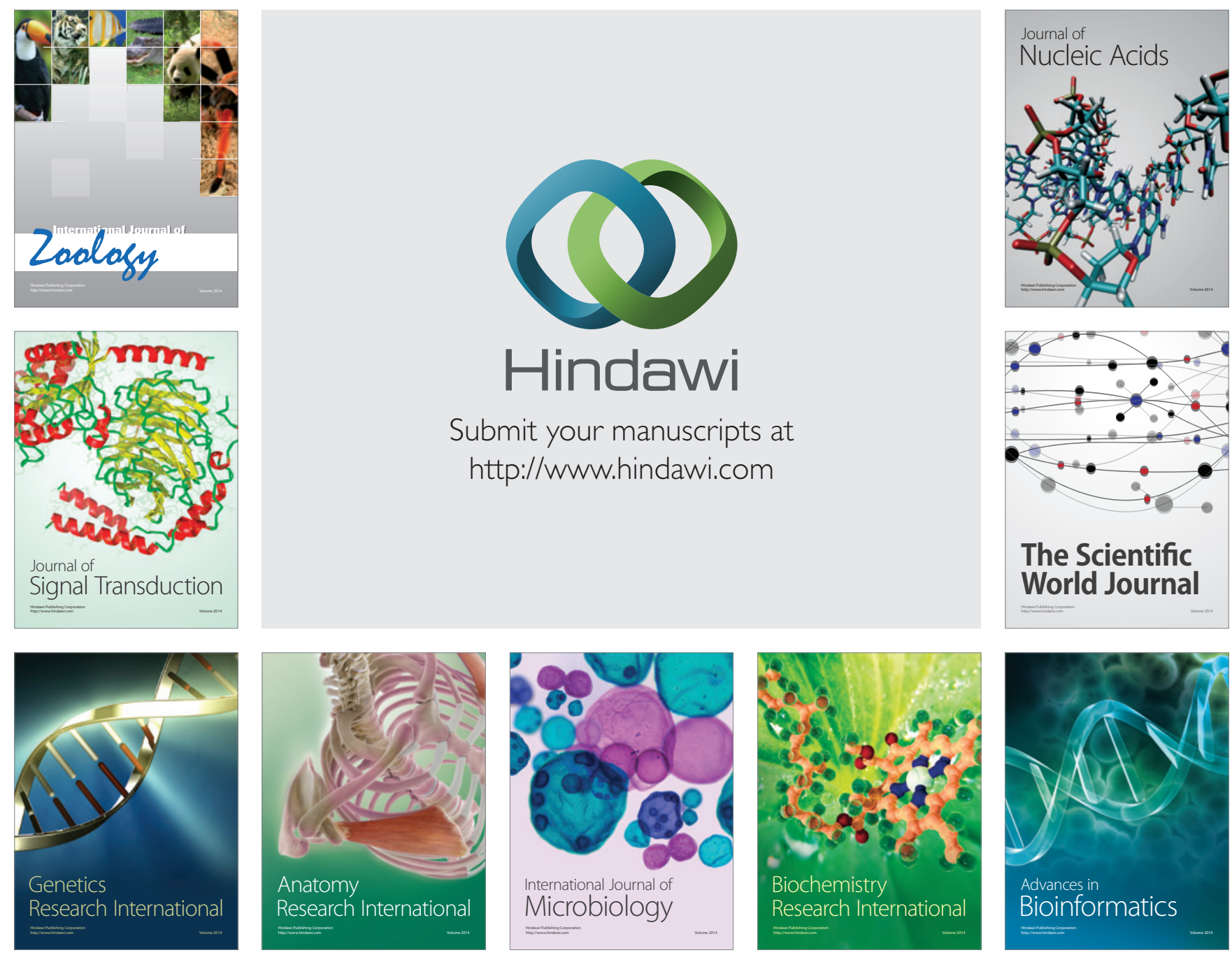

The Scientific World Journal
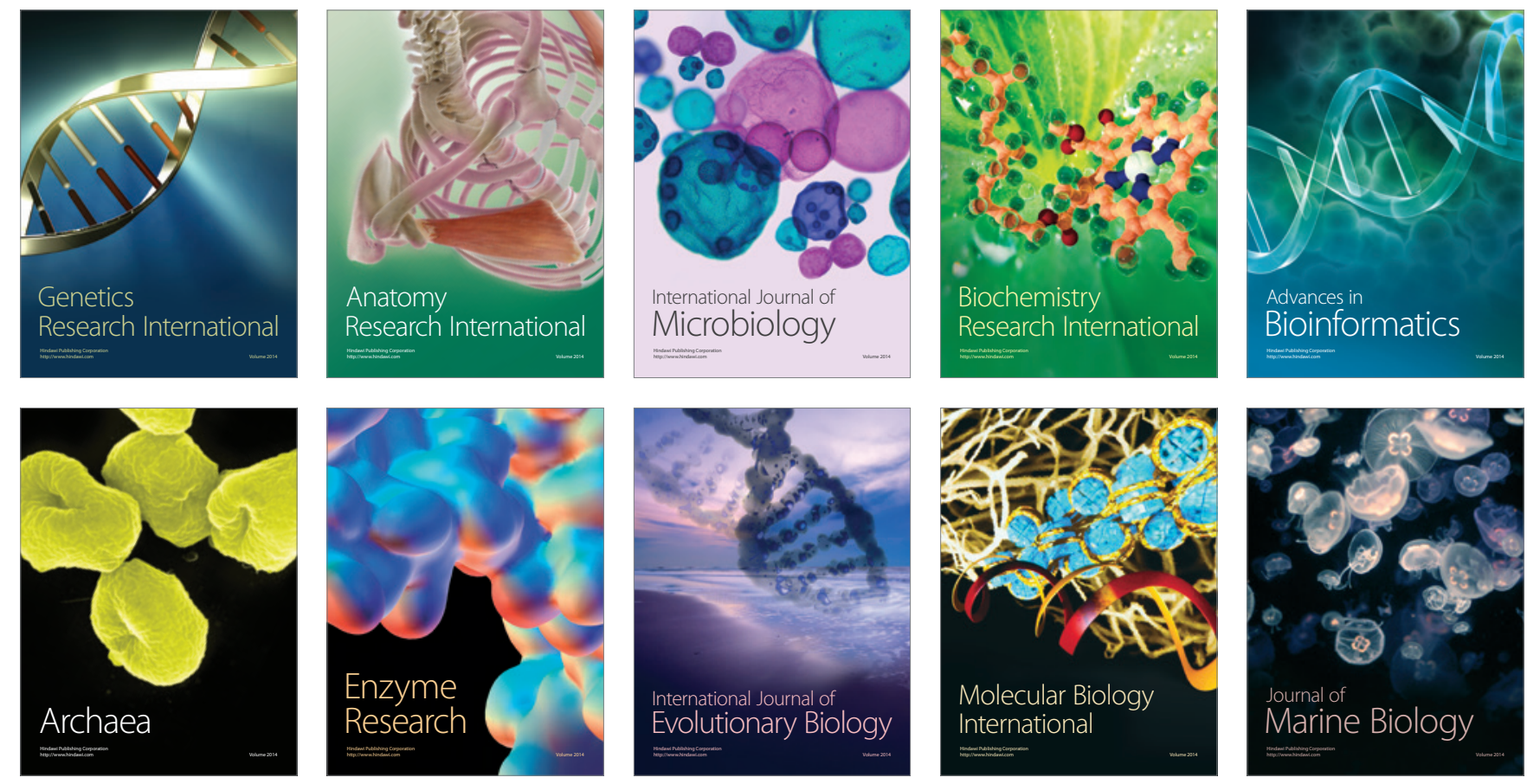